\title{
Study on Braking Energy Recovery of Four Wheel Drive Electric Vehicle Based on Driving Intention Recognition
}

\author{
Feihu Xuan, Huanhuan Zhang, Wenwen Xiao \\ College of Automotive Engineering, Shanghai University of Engineering Science, Shanghai, China \\ Email: 814177736@qq.com
}

How to cite this paper: Xuan, F.H., Zhang, H.H. and Xiao, W.W. (2018) Study on Braking Energy Recovery of Four Wheel Drive Electric Vehicle Based on Driving Intention Recognition. Open Access Library Journal, 5: e4295.

https://doi.org/10.4236/oalib.1104295

Received: December 28, 2017

Accepted: January 21, 2018

Published: January 24, 2018

Copyright $\odot 2018$ by authors and Open Access Library Inc.

This work is licensed under the Creative Commons Attribution International License (CC BY 4.0).

http://creativecommons.org/licenses/by/4.0/

\begin{abstract}
To judge the driver's driving intention can effectively improve the car braking energy recovery. Aiming at the problem of braking energy recovery of four wheel drives electric vehicle, combined with the main restrictive conditions of ECE regulations, motor characteristics and battery SOC, a braking force distribution strategy for different braking intention is established. The MATLAB/ Simulink platform is used for modeling and simulation to verify the effectiveness of the braking energy recovery strategy, and verify the compliance of the braking strategy through the braking distance under the initial braking speed specified in the national standard. The results show that the fuzzy recognition model can accurately identify the various brake driving intentions, according to different driving intention under the brake, braking force distribution strategy are established, which is effective in the initial braking speed under different braking distance is also in line with national standards.
\end{abstract}

\section{Subject Areas}

Mechanical, Engineering, Automata

\section{Keywords}

Driving Intention, Energy Recovery, Fuzzy Control, Four Wheel Drive

\section{Introduction}

The shortage of oil resources and environmental pollution has seriously affected people's lives. Therefore, the attention of the whole society and the government 
has been aroused by this kind of environment [1]. The four wheel hub motor independent drive electric vehicle has gained the attention of experts and scholars at home and abroad because of its advantages of simplified traditional system, saving space and flexible motor control, compared with the advantages of ordinary electric vehicle, and they achieved fruitful research results through efforts. In the key technology of the electric vehicle, the regenerative braking technology can reclaim the braking energy and increase the driving range of the electric vehicle. The electric vehicle with the braking energy recovery function also has the motor brake system and the mechanical brake system. The reasonable distribution of the mechanical brake system and motor regenerative braking system can guarantee the automobile brake under the condition of a large number of braking energy recoveries, therefore, introducing the driving intention through the judgment and the purpose of the driver to judge can identify a variety of braking intention mode, and then matching between mechanical braking force and braking force for various motor's braking mode, the idea of this study is on the basis of this [2].

\section{Research on Driving Intention Recognition}

In this paper, the acceleration pedals displacement, brake pedal displacement, brake pedal displacement rate, speed, and driving intention identification parameters is used in this paper. According to the current vehicle speed, the braking intention can be divided into high-speed braking mode, medium speed braking mode and low speed braking mode. Then the three braking modes are divided into emergency braking mode, general braking mode and slow braking mode respectively. There are three kinds of high speed braking mode: high speed emergency braking mode, high speed general braking mode and high speed flat brakes mode. There are also three kinds of medium speed braking mode: medium speed emergency brake mode, medium speed general brake mode and medium speed slow braking mode. In low speed braking mode, the classification of brake conditions is not very obvious because of the high or low braking strength, so it is set as a mode, that is, low speed braking mode [3].

The process of braking intention recognition is as follows: firstly, by judging the vehicle speed is in high speed, medium speed or low speed, and then through the displacement of brake pedals and the accelerator pedal position if there is a change to determine whether the driver braking operation, if the acceleration pedal and brake pedal has changed, the judgment at this time for the wrong operation mode wrong operation mode after the action requires specific judgment according to the speed. If the speed is in the low speed mode at this time, it is judged to be the acceleration mode. If the speed is in the middle and high speed mode [4], the braking mode is judged, and the emergency braking is carried out. If judged to be in the braking mode at this time, according to the change rate of accelerator pedal and accelerator pedal, we can judge whether the vehicle is in an emergency braking state, a general braking state or a slow braking state mode [5]. 


\section{Research on Regenerative Braking Control}

\subsection{Restraint Condition Analysis of Regenerative Braking of Wheel Motor}

1) ECE regulation

2) In order to ensure the directional stability and sufficient braking efficiency of brake, the ECE R13 brake regulations formulated by the European Economic Commission of the United Nations put forward a clear request for the braking force of front axle and rear wheel brake of double axle vehicle. Provisions of the industry standard ZBT 24007-1989 in our country have made similar requirements, regulations for all kinds of vehicles: $=0.2 \sim 0.8$, brake strength, vehicles under various loading conditions, the adhesion coefficient curve in the rear axle utilization adhesion coefficient curve using the front axle for car, brake strength in $0.3 \sim 0.4$ between the rear axle the adhesion coefficient curve does not exceed the line conditions, allowing the rear axle utilization adhesion coefficient curve before and after using the above adhesion coefficient curve.

3) The limit of the peak torque of the wheel motor

4) During the braking energy recovery process of the four wheel hub motor driven electric vehicle, the motor cannot be charged without restriction due to the limitation of the SOC value of the battery. However, the braking force required by automobile brake is greater than that of the maximum torque of the hub motor, so that the braking force of the hub motor cannot exceed the peak torque of the motor itself. By comprehensive consideration, the maximum braking force of the motor should be the minimum between two cases.

5) Battery constraints

6) The battery used in this paper is lithium battery. When braking, the power generated by the hub motor is less than the charging efficiency of the rechargeable battery, so as to avoid damaging the battery. At the same time, check the battery SOC value before charging. Only when the SOC value of the battery is less than 0.94 , can it be charged. When the SOC value of the battery is greater than 0.94 , it cannot be charged.

\subsection{Analysis of Regenerative Braking Strategy}

When the four wheel hub motor driven electric vehicle carries out the braking energy recovery, the braking force distribution will be maximized under the premise of ensuring driving safety and the braking energy is maximized. The distribution of braking force mainly includes two aspects, one is the distribution of braking force on the front and rear axle, the other is the distribution between motor braking force and mechanical braking force.

By car theory, the front and rear wheel and lock when curves of front and rear wheel brake force is the ideal of the front and rear brake force distribution curve, referred to as curve.

The dynamic relationship between the front and back axes of the full ideal braking force distribution is as follows: 


$$
F_{\mu 2}=\frac{1}{2}\left[\frac{G}{h_{g}} \sqrt{b^{2}+\frac{4 h_{g}}{G} F_{\mu 1}}-\left(\frac{G b}{h_{g}}+2 F_{\mu 1}\right)\right]
$$

$F_{\mu 1}$ Braking force for front wheel brake; $b$ for the distance between the center line of the car's center of mass and the rear axle; $G$ for car gravity; $h_{g}$ is the height of the car's center of mass; $\frac{\mathrm{d} u}{\mathrm{~d} t}$ for automobile speed reduction; $F_{\mu 2}$ for brake force of rear wheel brake.

The distribution strategy of this paper is based on the principle that the braking energy can be recovered as much as possible under the premise of ensuring the safety of the brake.

Through the fuzzy recognition model can be identified at this time at the car braking mode: high speed high speed braking emergency braking mode, general mode, high speed, medium speed smooth braking mode in emergency braking mode, general speed braking mode, automatic mode, automatic speed and medium speed flat mode. Different braking force distribution of machinery and motor is carried out according to each braking mode. The following is the specific allocation strategy:

High speed emergency braking situation, because the motor braking force response speed cannot meet the requirements of braking torque, and easy to trigger ABS in an emergency braking situation, the brake control system complexity increases, therefore, based on security, brake mechanical brake system of high speed in an emergency braking situation, front and rear wheel follow the front and rear wheel braking force distribution of braking force distribution coefficient.

In the case of high speed general braking, the total braking force required in high speed braking is slightly smaller than that in the case of high speed emergency braking. At this point, the safety factors are still very heavy, and the braking energy recovery is properly carried out. Therefore, the mechanical braking force and the motor braking force are braking at the same time, the braking force is greater than the motor braking force, and the braking force of the motor is not at the maximum value state. At this time, the braking force distribution coefficient of the front and rear wheels brakes still follows the mixed braking force.

High speed smooth braking, high speed compared to the normal braking condition, the smaller the total braking force needed at this time, in view of the braking speed, the safety factor is more important, and considering the braking energy recovery, while still using mechanical braking force and braking force and braking motor, but compared to the general high speed braking. Mechanical braking force to continue to reduce the motor braking force continues to increase. And the overall braking force still follows the braking force distribution coefficient of the front and back brakes.

For medium speed emergency braking, considering the safety consideration, mechanical braking force is still used. Mechanical braking force follows the 
brake force distribution coefficient of front and rear brake.

Medium speed general braking, medium speed and slow braking, the safety of vehicle is in a high state. At this time, considering the maximization of braking energy recovery, settled the motor peak braking torque, the insufficient braking force is supplemented by mechanical braking force.

In low speed mode, when the speed of the car is below $10 \mathrm{~km} / \mathrm{h}$, the mechanical braking force is all adopted because the energy recovery of the motor braking is small. The allocation of mechanical braking force distribution follows the distribution coefficient of braking force distribution of brake force 0.6.

Implementation of braking force distribution strategy in all modes before, in order to protect the battery from being damaged, need to go through the cell value of SOC, if SOC is greater than 0.95 , the battery based on security, not in charge, but the energy consumption brake, if the SOC value is less than 0.95 can be charged during charging, the battery state real-time monitoring SOC value.

\section{The Establishment and Analysis of the Simulation Model}

The vehicle simulation model built through Simulink is shown in Figure 1.

The simulation analysis of the braking process at different initial speeds braking speed, braking distance, battery SOC Qu Xianru Figures 2-4 for low speed and slow braking with initial speed of $30 \mathrm{KM} / \mathrm{h}$.

As shown in Figures 2-4, the braking time is $3.6 \mathrm{~s}$, the braking distance is $15.2 \mathrm{~m}$,

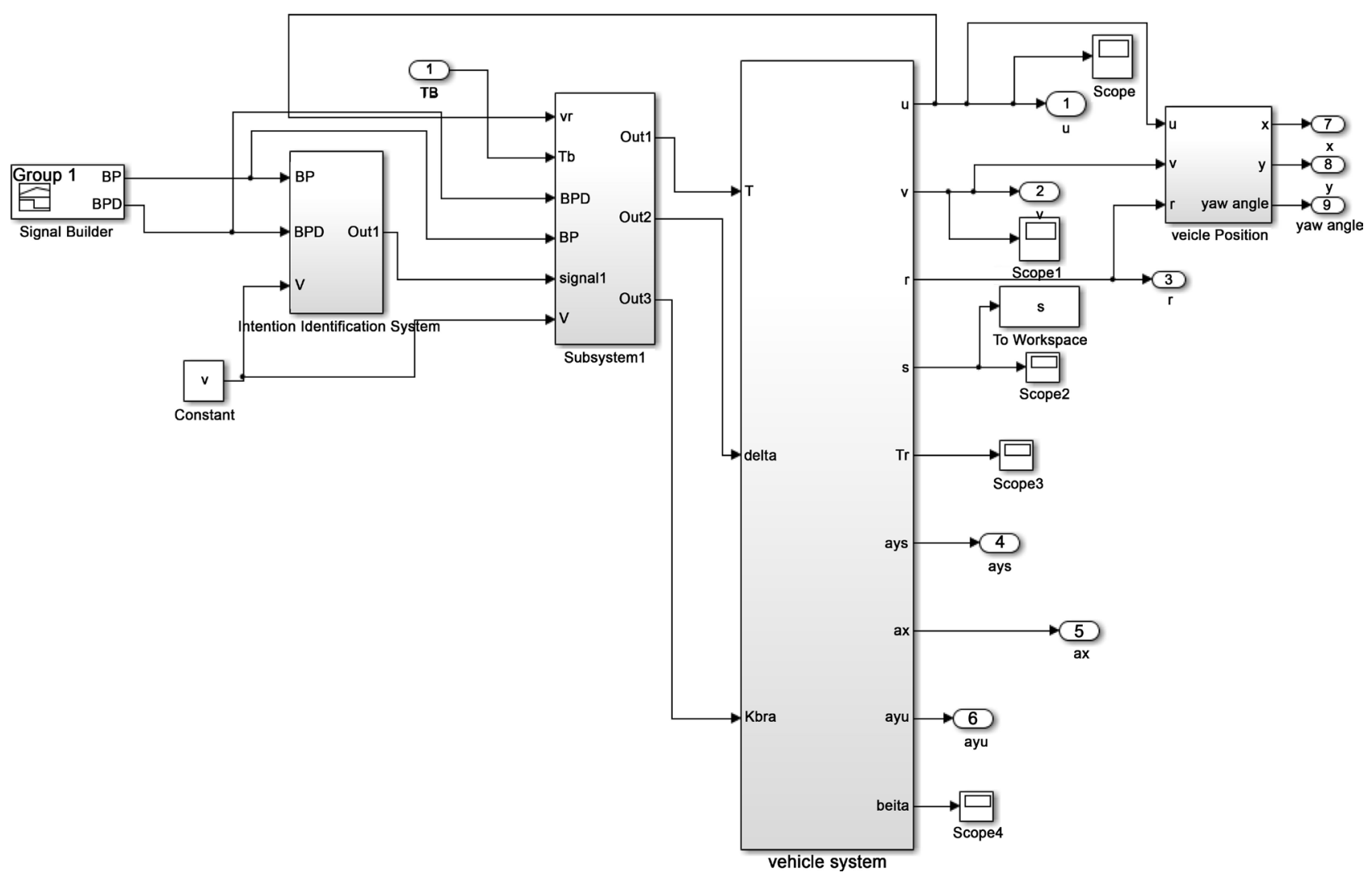

Figure 1. Simulink vehicle model. 


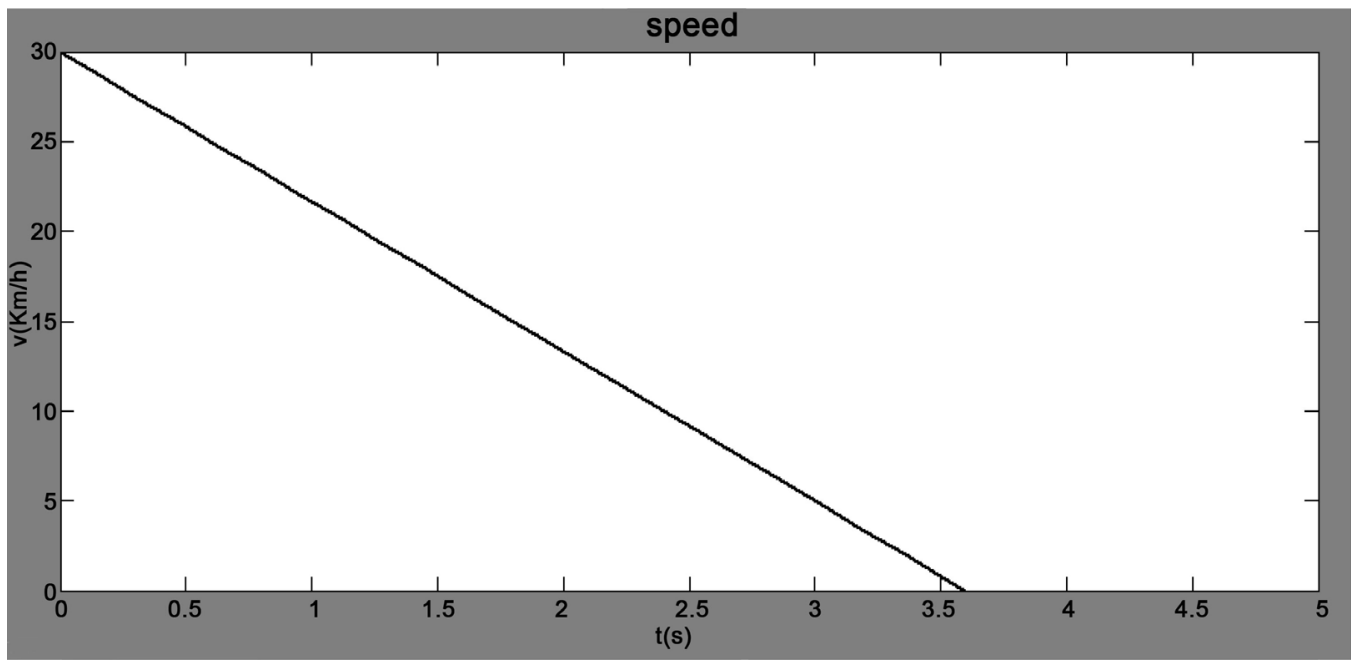

Figure 2. Speed variation curve of initial velocity for $30 \mathrm{~km} / \mathrm{h}$.

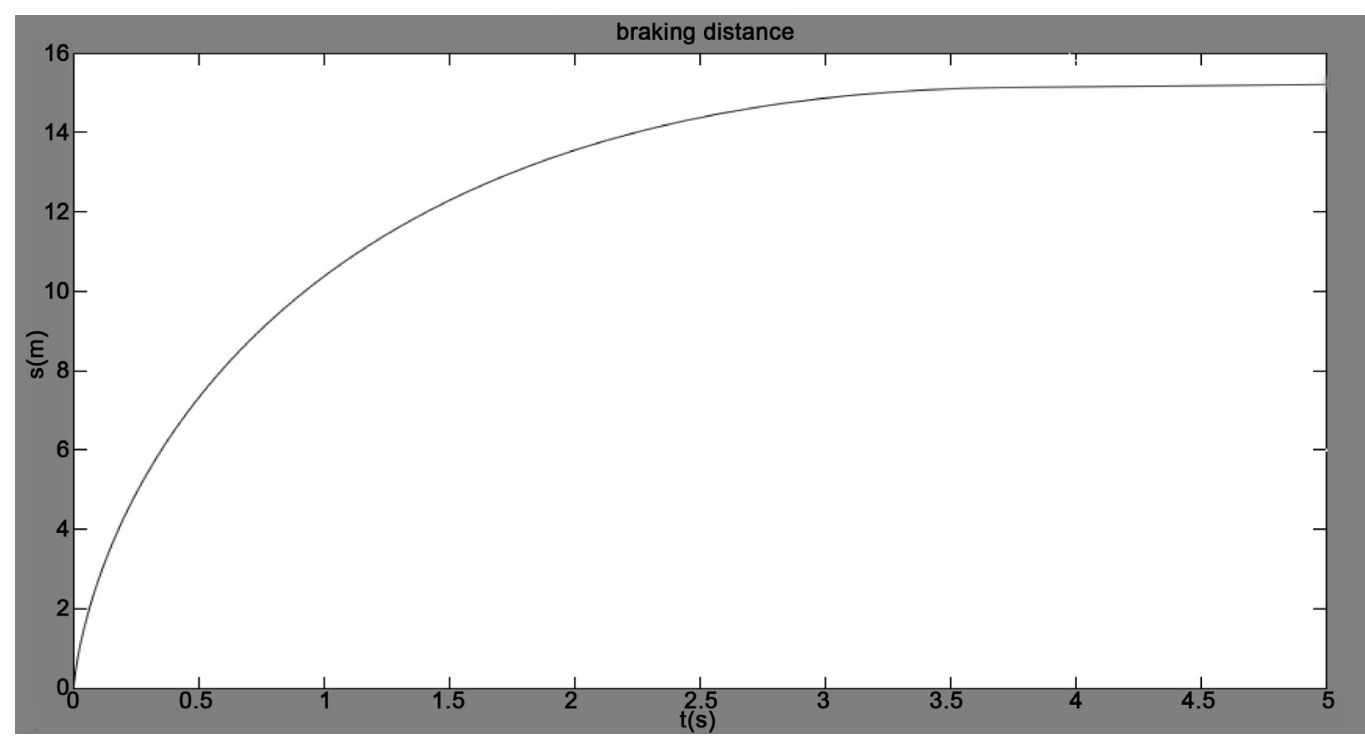

Figure 3. The change curve of braking distance when the initial velocity is $30 \mathrm{~km} / \mathrm{h}$.

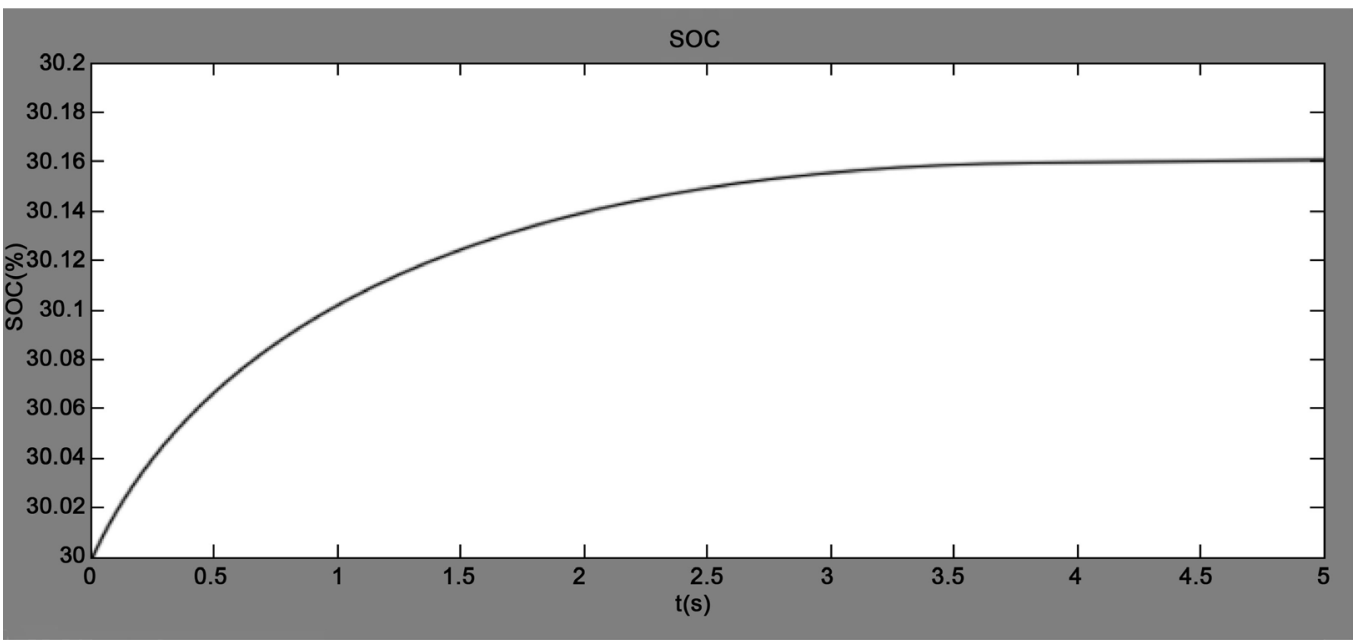

Figure 4. The change curve of SOC of the battery when the initial velocity is $30 \mathrm{~km} / \mathrm{h}$. 
and the SOC is stable at 30.16 at the initial speed of $30 \mathrm{KM} / \mathrm{h}$.

Braking speed, braking distance, battery SOC Qu Xianru Figures 5-7 for low speed and slow braking with initial speed of $40 \mathrm{KM} / \mathrm{h}$.

As shown in Figures 5-7, the braking time is $5.3 \mathrm{~s}$, the braking distance is 36 $\mathrm{m}$, and the SOC is stable at 30.98 at the initial speed of $30 \mathrm{KM} / \mathrm{h}$.

Braking speed, braking distance and battery SOC Qu Xianru diagram of a low speed and flat brake with initial speed of $100 \mathrm{KM} / \mathrm{h}$.

As shown in Figures $8-10$, the braking time is $311 \mathrm{~s}$, the braking distance is $138 \mathrm{~m}$, and the SOC is stable at 35.60 at the initial speed of $1000 \mathrm{KM} / \mathrm{h}$.

From the above three different initial speed of braking can be seen. Under the same pedal opening, opening change rate and SOC value, with the increase of initial braking speed, when the vehicle speed drops smoothly, the SOC value increases with the increase of initial braking speed, and the braking distance increases with the increase of initial braking speed. Through simulation, the lower

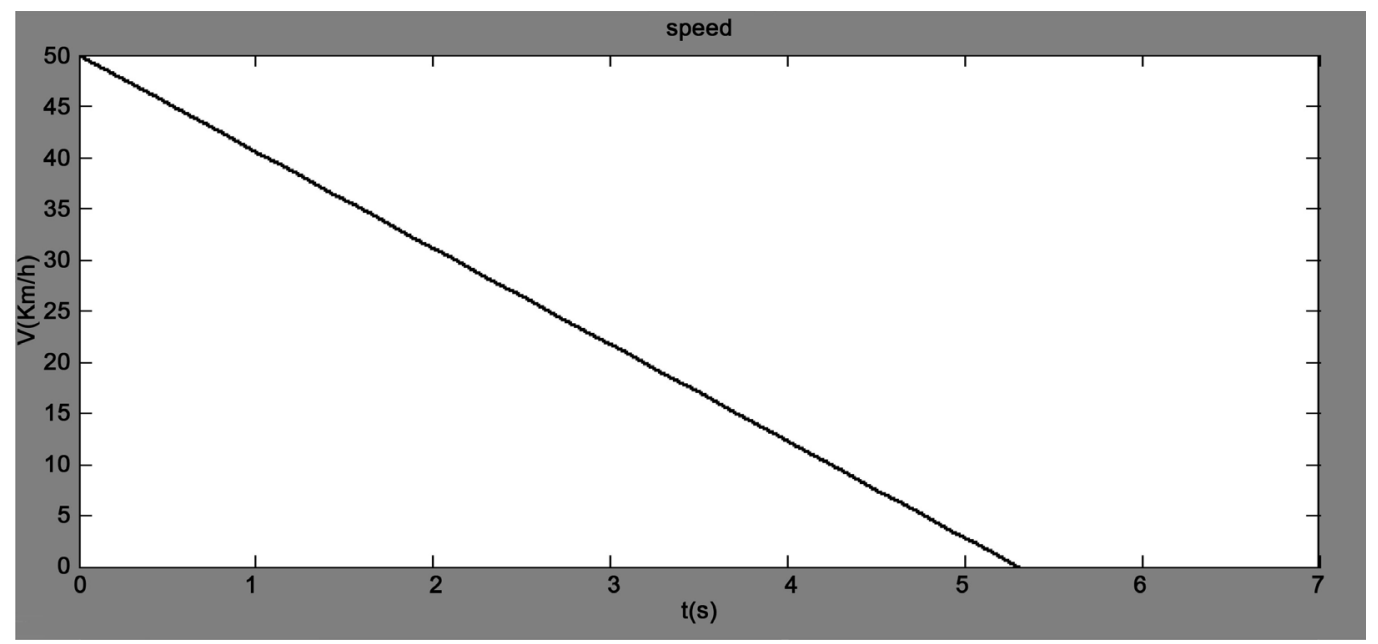

Figure 5. Speed variation curve of initial velocity for $40 \mathrm{~km} / \mathrm{h}$.

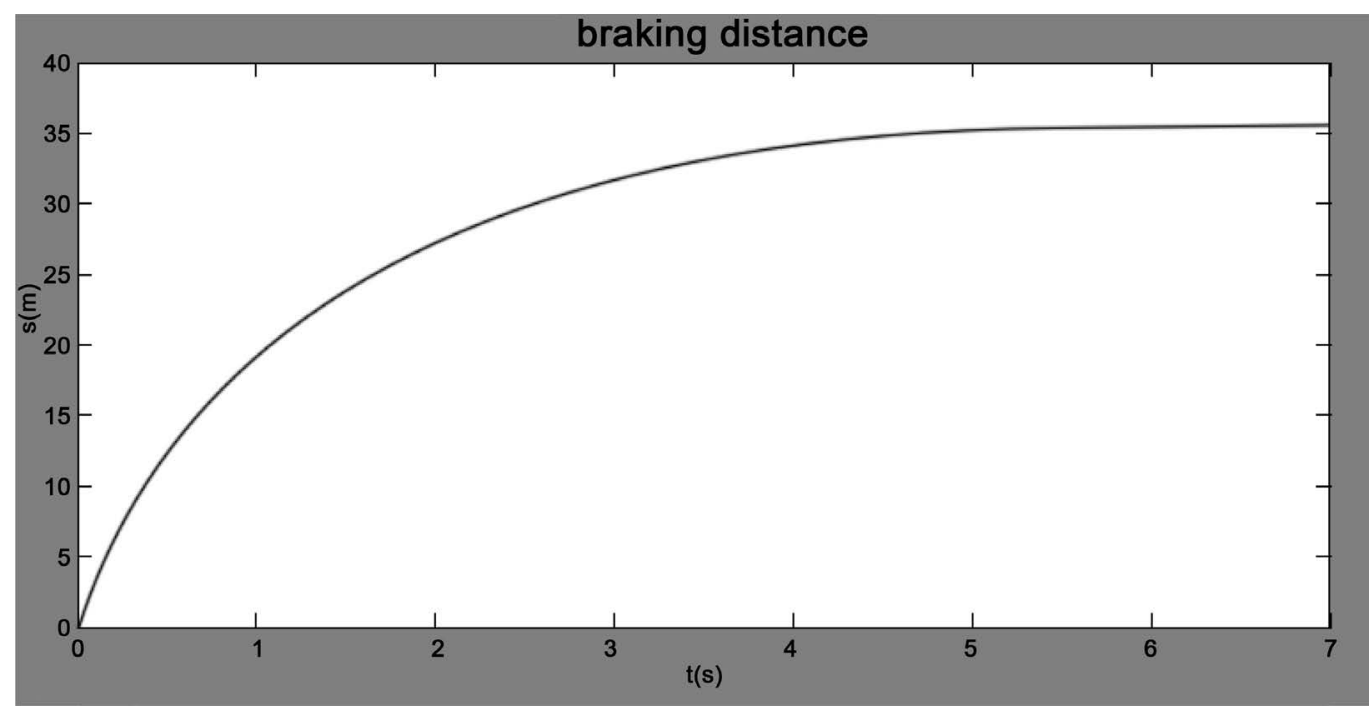

Figure 6. The change curve of braking distance when the initial velocity is $40 \mathrm{~km} / \mathrm{h}$. 


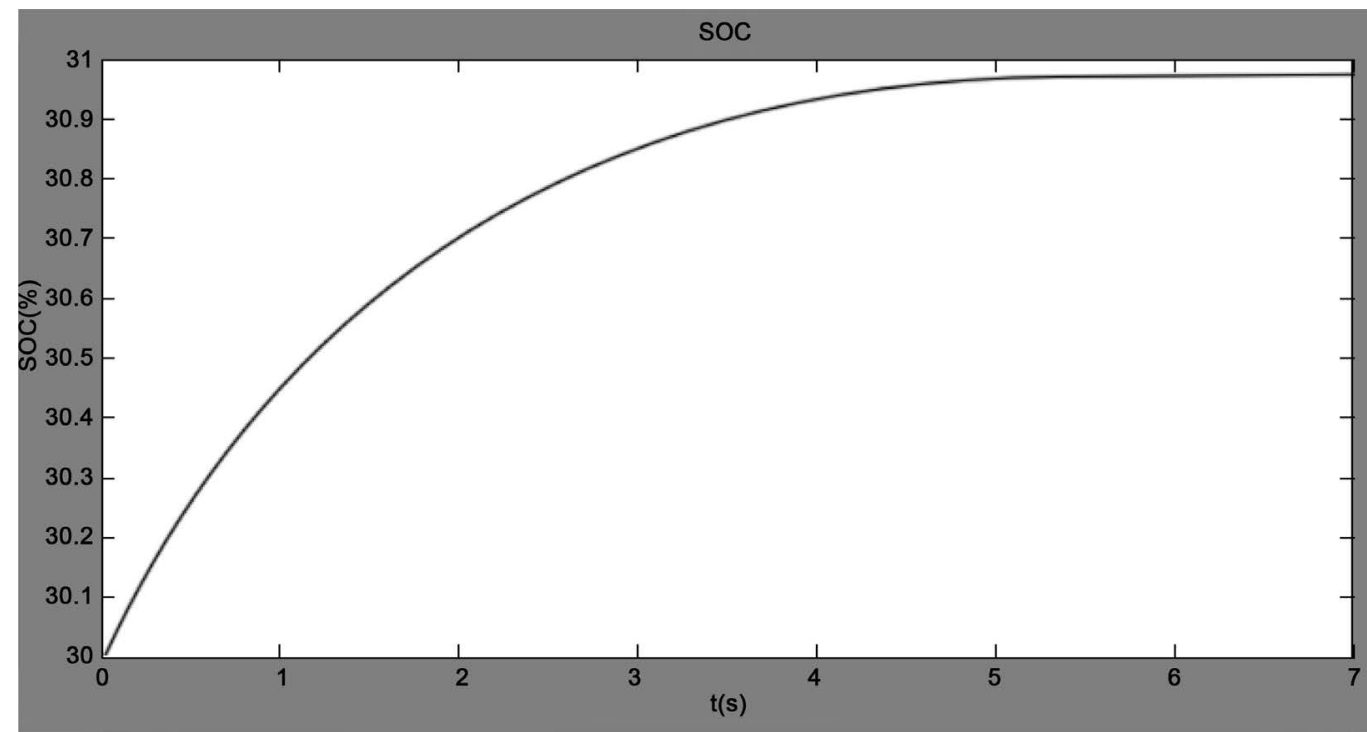

Figure 7. The change curve of SOC of the battery when the initial velocity is $40 \mathrm{~km} / \mathrm{h}$.

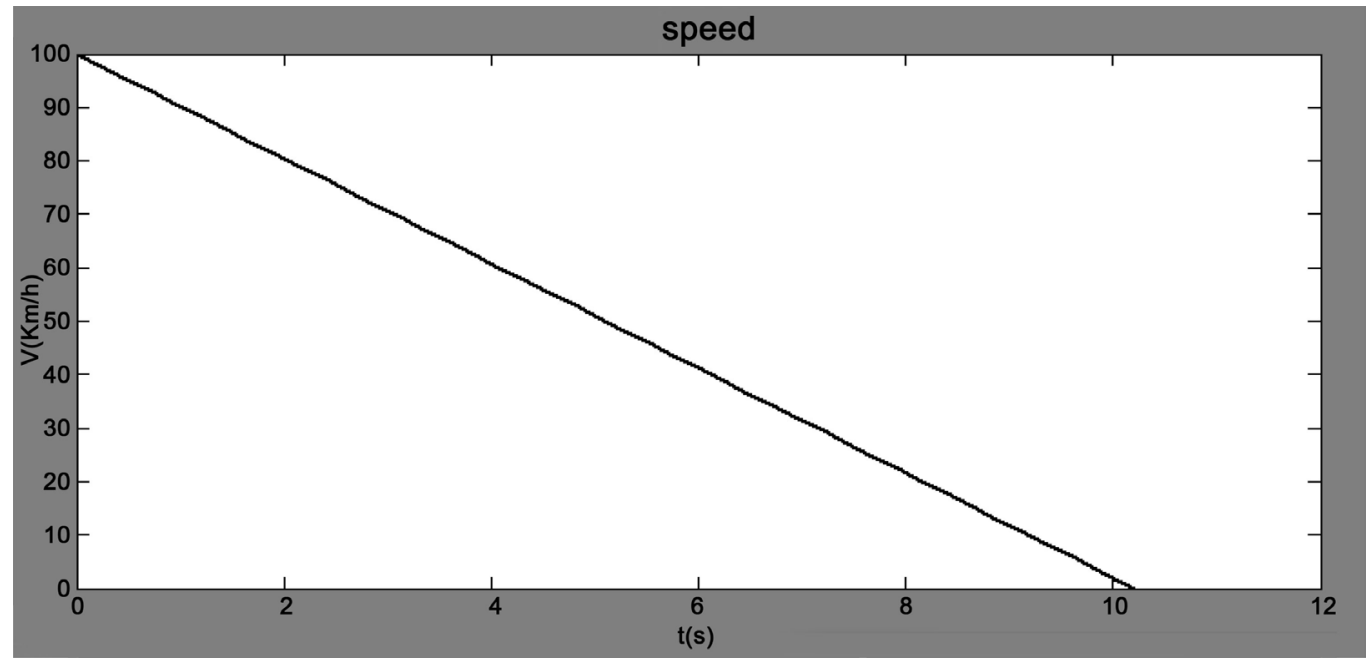

Figure 8. Speed variation curve of initial velocity for $100 \mathrm{~km} / \mathrm{h}$.

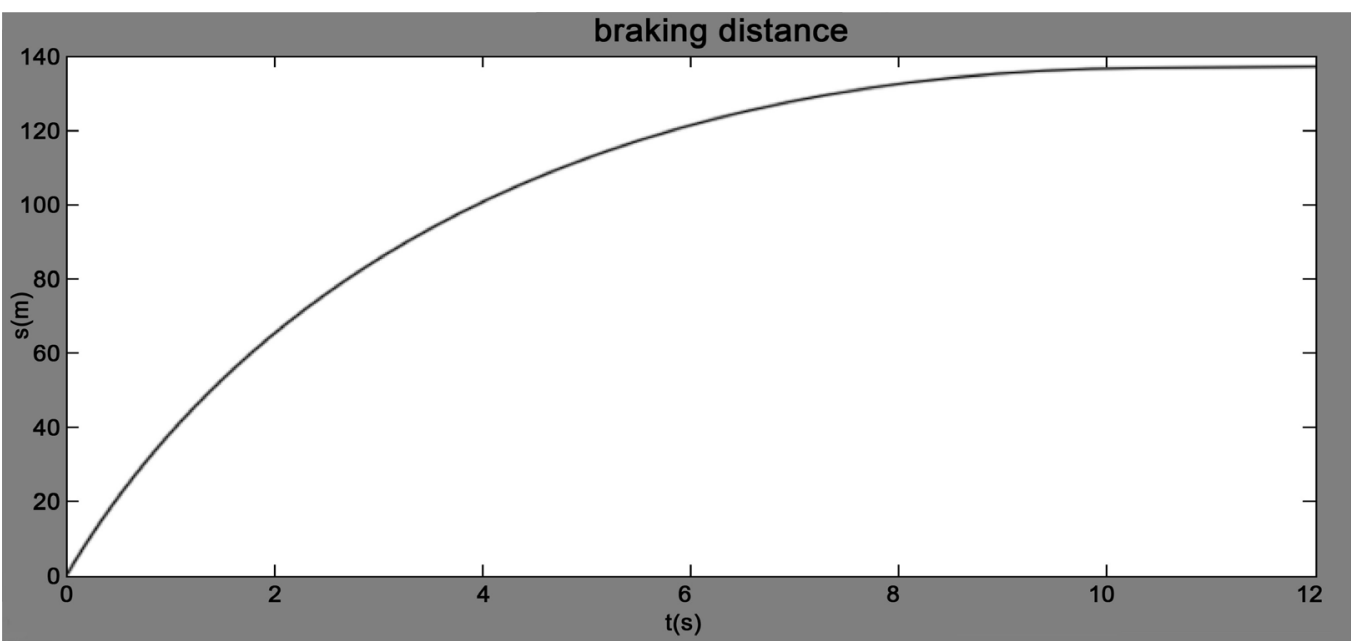

Figure 9. The change curve of braking distance when the initial velocity is $100 \mathrm{~km} / \mathrm{h}$. 


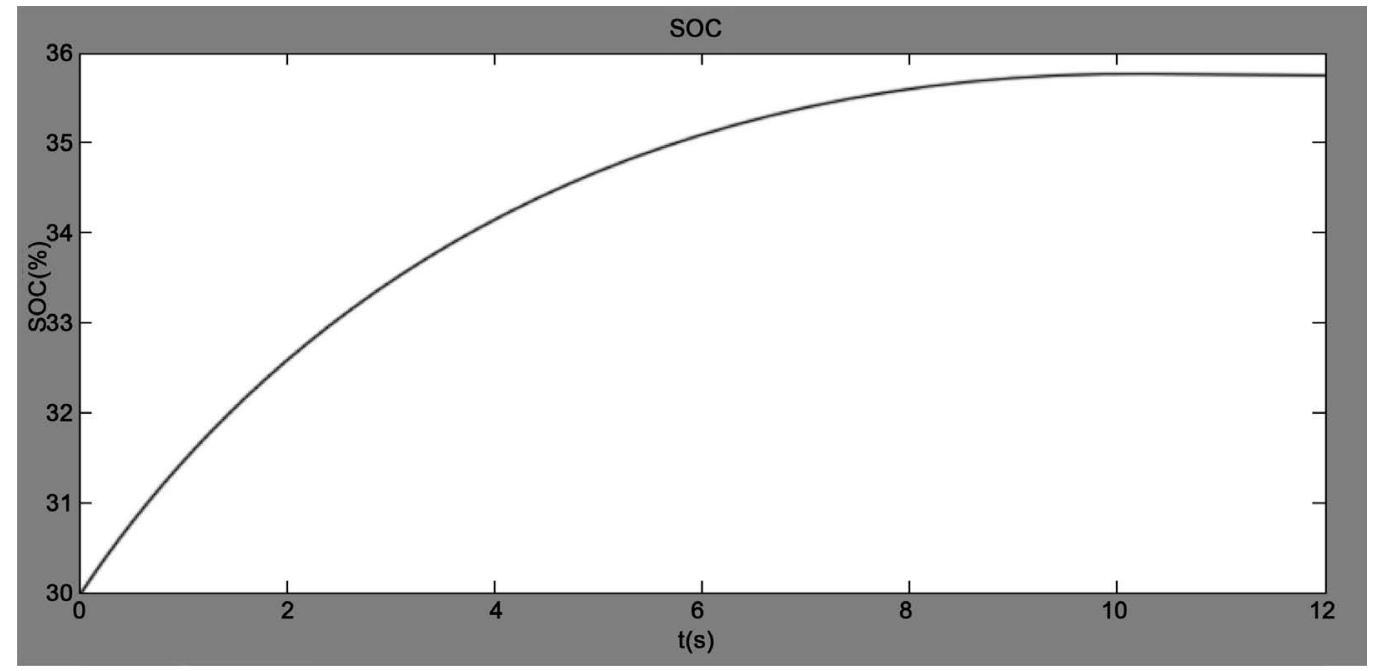

Figure 10. The change curve of SOC of the battery when the initial velocity is $100 \mathrm{~km} / \mathrm{h}$.

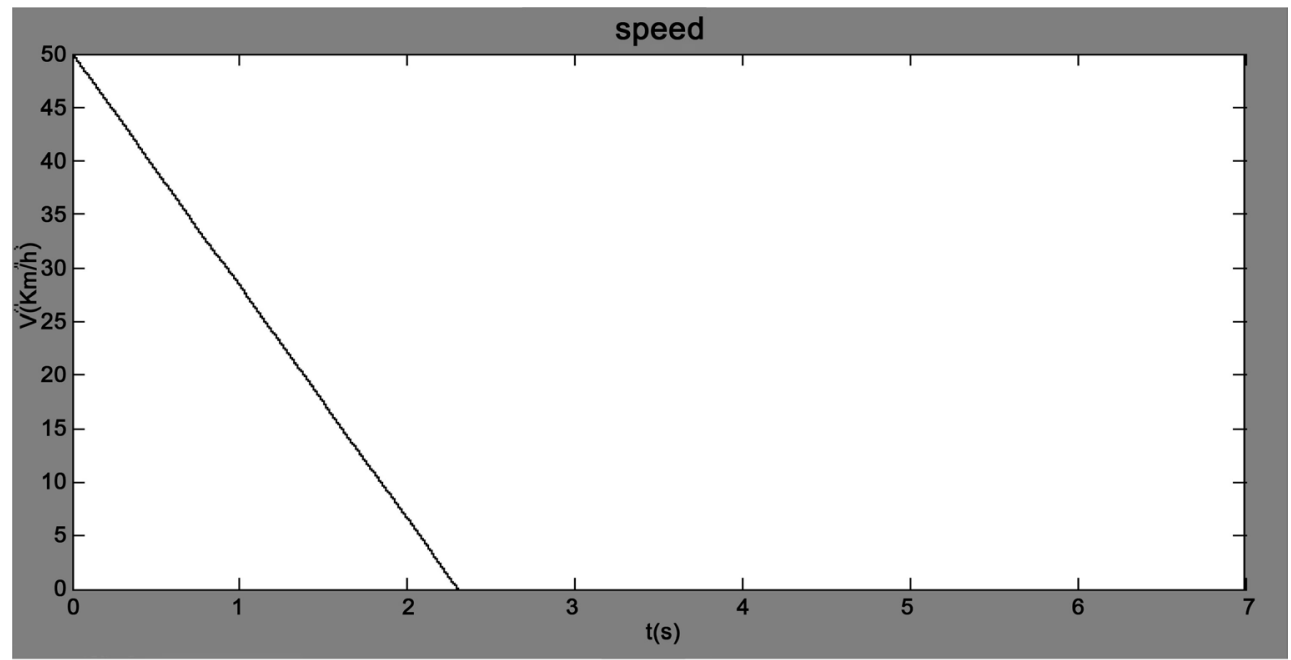

(a)

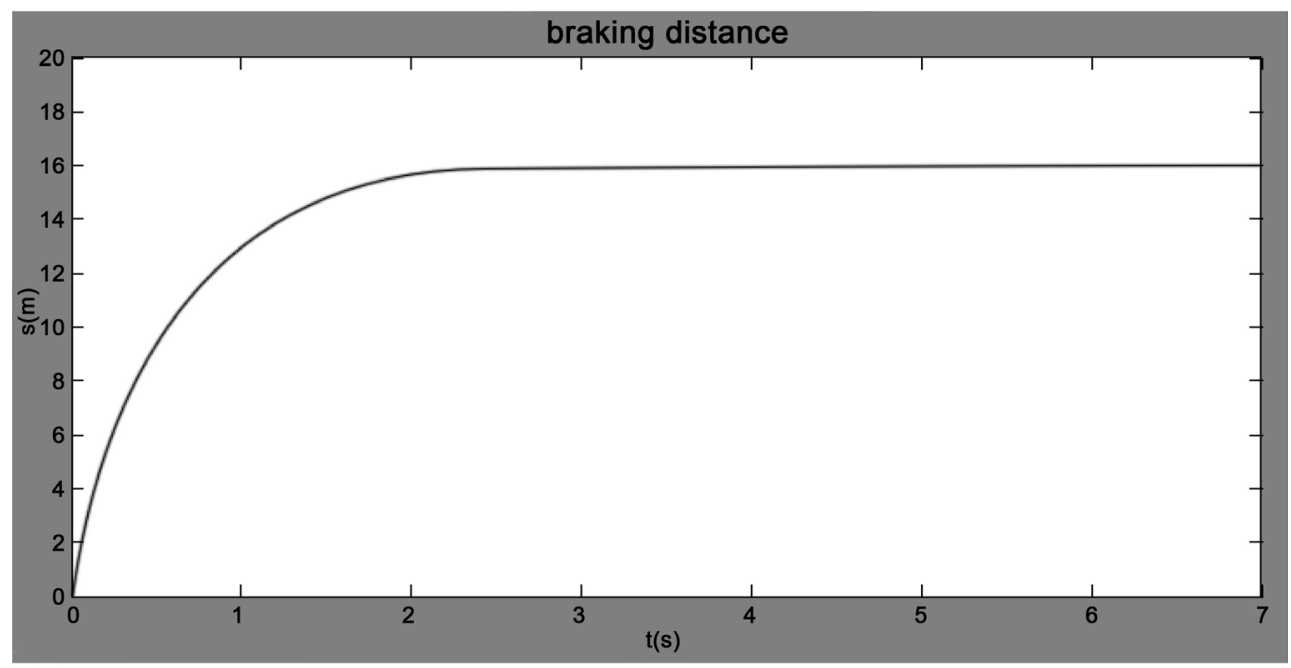

(b)

Figure 11. (a) Initial speed of $40 \mathrm{~km} / \mathrm{h}$ emergency braking speed change curve; (b) Initial speed of the 40 $\mathrm{km} / \mathrm{h}$ emergency braking distance change curve. 
table SOC data are obtained.

The braking distance of the vehicle during emergency braking of $50 \mathrm{~km} / \mathrm{h}$.

The brake pedal opening change rate is stepped on the $300 \mathrm{~mm} / \mathrm{s}$, the brake pedal opening is 1 , and the change curve of the brake speed is shown in Figure 11.

\section{Conclusion}

It can be seen from the simulation that the braking distance of $50 \mathrm{~km} / \mathrm{h}$ is $16 \mathrm{~m}$ in the case of emergency braking. According to the regulation of national standard G7258 2012, when the vehicle is empty, the brake pedal is pressed on the initial speed of $50 \mathrm{~km} / \mathrm{h}$, and the distance it passes is no more than $19 \mathrm{~m}$ when the vehicle stops completely, which is in conformity with the regulations, which validates the validity of the braking strategy.

\section{References}

[1] Osborn, R.P. and Shim, T. Independent Control of All-Wheel-Drive Torque Distribution. SAE Paper 2004-01-2052.

[2] Kamachi, M. and Walters, K. (2006) A Research of Direct Yaw-Moment Control on Slippery Road for In-Wheel Motor Vehicle. The 22nd International Battery, Hybrid and Fuel Cell Electric Vehicle Symposium \& Exposition, Yokohama, 2122-2133.

[3] Motoki, S., Wang, Y.Q. and Masao, N. (2000) Motion Control of Electric Vehicles Considering Vehicle Stability. The 5 th International Symposium on Advanced Vehicle Control, Michigan, 122-133.

[4] He, P. and Yoichi, H. (2006) Improvement of EV Maneuverability and Safety by Disturbance Observer Based Dynamic Force Distribution. The 22nd International Battery, Hybrid and Fuel Cell Electric Vehicle Symposium \& Exposition, Yokohama, 1818-1827.

[5] Young-Min, J., Rammohan, M. and Minho, L. (2014) Driver's Lane-Change Intent Identification Based on Pupillary Variation. 2014 IEEE International Conference on Consumer Electronics, Taiwan, 197-198. 